\title{
Reflections from IDF-WDC 2015
}

\section{Dr Caroline Day reports from the International Diabetes Federation World Diabetes Conference in Vancouver, Canada, November 30th to December 4th 2015}

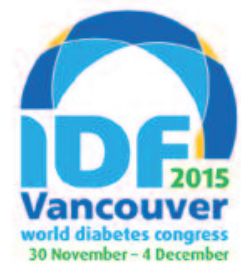

\begin{abstract}
Introduction
The Vancouver Convention Centre hosted more than 8000 delegates at the International Diabetes Federation (IDF) biennial World Diabetes Conference (WDC). British Columbia's largest city is one of the wettest in Canada - downtown Vancouver has an annual rainfall of 62 inches - but claims to enjoy the mildest winter temperatures on the Canadian mainland. Unlike the dull and drizzly weather, the meeting was motivational and bright.
\end{abstract}

\section{Satellites and sessions}

The satellite symposia were generally well attended, but of the 22 symposia - half of which were held prior to the scientific sessions - only four were accredited, two of which can be viewed online. 1,2 However, the scientific sessions were awarded 24 CMEs.

More than 1500 abstracts were included at IDF-WDC with about half being presented as posters and the remainder delivered orally across 10 parallel sessions invariably attractive sessions ran simultaneously. The programme provided for a plethora of interests and the UK was well represented amongst the presenters. In addition to the IDF Lectures (Table 1), there were excellent review and update lectures surfing the webcasts is highly recommended. A USB stick (supplied by AstraZeneca when the trade exhibition opened on 1st December) replaced the traditional Abstract book, but abstracts can now be accessed online, ${ }^{3}$ as can posters and webcasts of the scientific programme. ${ }^{4}$

\section{IDF Atlas 2015}

The 7th edition of the IDF Diabetes Atlas available in print as well as online - was launched at the conference..$^{5}$ It is slimmer than the previous edition with briefer appendices providing only data for 2015 . The projected world population will increase from today's 7.3 billion to 9 billion in 2040 . Rural depopulation, a shift to urban environments and diabetogenic lifestyles are expected to continue, leading to a $54 \%$ increase in the number of cases of diabetes (415 to 642 million) by 2040. This will add an additional $19 \%$ to global health spending on diabetes. The 2015 prevalences of
Table 1 IDF award lectures

IDF award lecture
Living with diabetes
Clinical science
Basic science
Public health and epidemiology
Education and integrated care
Diabetes in indigenous peoples

Global challenges in health

\section{Speaker and subject}

Ms Riva Greenberg, USA

The Flourishing Approach: A way to treat and live with diabetes that goes beyond coping

Professor Stephanie A Amiel, UK Sweet and low: How hypoglycaemia research might address the diabesity pandemic

Professor C Ronald Kahn, USA Cellular communication, insulin resistance and the pathogenesis of type 2 diabetes

Professor Edward Gregg, USA

Transitions in diabetes-related morbidity and their implications for prevention

Ms Anne Belton, Canada Diabetes education: Has it changed?

Professor Harriet V Kuhnlein, Canada Building food and nutrition security in Indigenous populations

Professor Paul Zimmet, Australia Diabetes and its drivers: The largest epidemic in human history? impaired glucose tolerance $(6.7 \%)$ and diabetes $(8.8 \%)$ are predicted to rise to $7.8 \%$ and $10.4 \%$, respectively, by 2040 .

\section{Enhancing capacity}

The Pubic Health Foundation of India (PHFI), in association with the government of India and the IDF, launched the Diabetes Capacity Enhancement Programme. This will bring together specialists from the South Asian continent to share their expertise on the prevention of diabetes and its complications, care of people with diabetes and management systems, including workforce development to expand professional capacity to deal effectively with the increasing prevalence of diabetes in the region.

\section{Eye health}

The Fred Hollows Foundation announced the availability of Diabetes Eye Health: A Guide for Health Professionals, a document specifically written for primary healthcare practitioners. The guide and an associated PowerPoint presentation can be accessed via www.idf.org/eyehealth.

\section{The Vancouver Proclamation}

The Parliamentarians for Diabetes Global Network (PDGN), which was founded at the 2013 IDF-WDC in Melbourne, ${ }^{6}$ met in Vancouver and reported on progress in implementing the Melbourne Declaration. Motions and debates have been instigated in parliaments around the world, and diabetes as a largely treatable non-communicable disease (NCD) has been raised to the international agenda. The Vancouver Proclamation was signed by parliamentarians from more than 60 countries. This calls on governments to prioritise the United Nations Global Health Targets for diabetes (providing access to universal health coverage for everyone with diabetes) and members of the PDGN committed to campaigning to facilitate change.

\section{NCD Café}

NCDs - including diabetes - cause an estimated 36 million deaths a year, which is greater than all other diseases combined. The NCD Alliance (a multisectorial partnership of which the IDF is a founder member) 
hosted a series of interactive sessions at the NCD Café. Practical approaches to advocacy and implementation of change were discussed with experiences from diabetes and other NCDs, enhancing awareness of opportunities, highlighting obstacles and providing inspiration.

\section{Advocacy and action}

The coming together of advocacy and action was exemplified in a poster describing the journey to secure a regular supply of insulin to patients in Malawi and ensure a continuity of supply following completion of the initiating project. A direct procurement system has been established and the taskforce is maintaining pressure for the supplier discount to be passed down the chain to diabetes patients. ${ }^{7}$

The IDF Life for a Child programme currently helps more than 17,000 youngsters in 46 countries access insulin and necessary diabetes care, and the Kids and Diabetes in
School (KiDs) project aims to increase awareness of the needs of pupils with diabetes and provide staff training (www.idf.org/education/kids). The Diabetes Education Network for health professionals (D-NET) is an online platform (www. d-net.idf.org) connecting over 2500 members worldwide to communicate and learn about topical issues in diabetes education and care.

\section{IDF-WDC 2017}

If an average temperature of $21^{\circ} \mathrm{C}, 10$ hours of sunshine a day and no rain in December sounds enticing, start preparing for the 2017 IDF-WDC in Abu Dhabi.

\section{References}

1. Connecting care in type 2 diabetes: Implementing a multidisciplinary team http://www.effectivediabetesmanagement.com/

2. Weight management across the prediabetesdiabetes spectrum. http://www.effectivediabetesmanagement.com/
3. IDF-WDC 2015. Abstracts. http://www.idf.org/ files/abstracts/data/HtmlApp/main.html

4. IDF-WDC 2015. Scientific sessions. http:// www.idf.org/worlddiabetescongress/programme/scientific-programme

5. IDF Diabetes Atlas 2015, 7th edition. International Diabetes Federation, Brussels, 2015 www. diabetesatlas.org

6. Sanders AM. The Melbourne Declaration on diabetes. Br J Diabetes Vasc Dis 2014;14:357 .

7. Meanwell D, Ngoma NJ, Ntambalika T, et al. Access and affordability of insulin in Malawi: enhancing stakeholder and patient empowerment. IDF-WDC 2015, Abstract: 0719-PD. file:///G:/data/HtmlApp/main.html\#0

Dr Caroline Day Visiting Fellow, Diabetes Group, Aston University, Birmingham B4 7ET, UK E-mail: cday@mededuk.com

http://dx.doi.org/10.15277/bjd.2016.064 Br J Diabetes 2016;16:37-38

\title{
Non-communicable diseases programme in West Africa
}

\author{
Dr Alero Adjene, reports on the recent RCP clinical teaching visits to West Africa
}

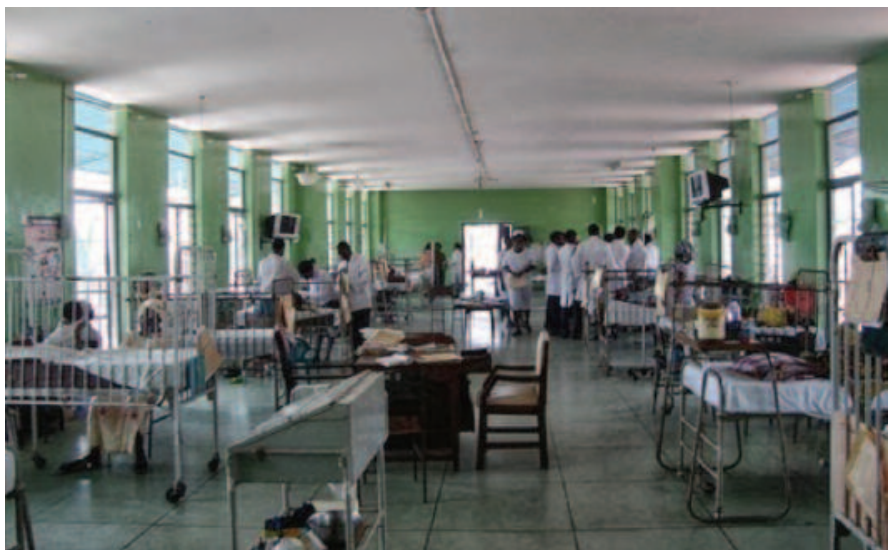

"Doctor, I can no longer perform!" These words, when heard by physicians practicing in Calabar, a city in South Southern Nigeria, are synonymous with the onset of type 2 diabetes in a male patient. While economic forecasts have promised growth, listing Nigeria amongst emerging markets, my experience was that poverty remains the norm. When healthcare is unaffordable, it is unsurprising that diabetes complications are established at diagnosis.

My preparation for the recent clinical teaching visits to Nigeria unearthed many articles declaring non-communicable disease as the next epidemic to hit Africa; but the paucity of data means the true scale of the problem is unknown. This collaboration, between the West African College of Physicians and the Royal College of Physicians, is a sign of the times.

My two-week visit to Calabar was spread across different specialties; the bulk of my time with internal medicine and the rest divided between family medicine, obstetrics, emergency room staff and an impromptu visit to the naval hospital. All sessions were received enthusiastically and culminated in robust discussion. Power outages, infamous in Nigeria, were frequent and the junior doctors manned the generators.

During one clinical session the registrars presented a man with a chronic foot ulcer and underlying osteomyelitis; a self-employed market trader, he had been on the wards for weeks on intravenous antibiotics and subcutaneous insulin. We all agreed that his extended inpatient stay would have led to significant losses in his income, and the doctors marvelled at how such cases can be successfully managed in an ambulatory setting. His church was funding his medication and he lacked a reliable source of refrigeration upon discharge. However, metformin, one of the cheapest drugs available, had not been prescribed; it is underused in Calabar due to a fear of lactic acidosis, a phenomenon rarely seen if used as labelled. This case highlighted the importance of our visit; books and websites are no substitute for seeing medicine in practice and passing on experience between doctors, especially when the burden of diabetes is ever on the rise. Finally, why see a physician when there are other less costly "health providers"? A traditional healer, a nurseled private clinic ... these are some of a myriad of challenges faced by our West African colleagues.

Dr Alero Adjene, Consultant Endocrinologist Imperial College London Diabetes Centre, PO Box 48338, Abu Dhabi, United Arab Emirates. E-mail: ally_adjy@hotmail.com

http://dx.doi.org/10.15277/bjd.2016.063 Br J Diabetes 2016;16:38 